\title{
AU6121963
}

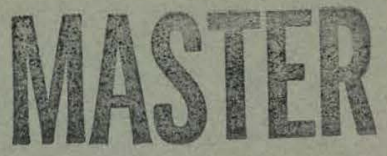

\section{THE PREPARATION OF RADIOACTIVE PHOSPHOROUS-32 SOURCES ON METAL PLATES}

R. E. Barringer

W. C. Dietrich

Y-12 PLANT

Oak Ridge, Tennessee

\section{APPROVED FOR PUBLIC RELEASE}

OAK RIDGE GASEOUS DIFFUSION PLANT OAK RIDGE Y-12 PLANT
OAK RIDGE NATIONAL LABORATORY

- PADUCAH GASEOUS DIFFUSION PLANT 


\section{DISCLAIMER}

This report was prepared as an account of work sponsored by an agency of the United States Government. Neither the United States Government nor any agency Thereof, nor any of their employees, makes any warranty, express or implied, or assumes any legal liability or responsibility for the accuracy, completeness, or usefulness of any information, apparatus, product, or process disclosed, or represents that its use would not infringe privately owned rights. Reference herein to any specific commercial product, process, or service by trade name, trademark, manufacturer, or otherwise does not necessarily constitute or imply its endorsement, recommendation, or favoring by the United States Government or any agency thereof. The views and opinions of authors expressed herein do not necessarily state or reflect those of the United States Government or any agency thereof. 


\section{DISCLAIMER}

Portions of this document may be illegible in electronic image products. Images are produced from the best available original document. 
Printed in USA. Price $\$ 1.00$. Available from the Clearinghouse for Federal Scientific and Technical Information, National Bureau of Standards, U.S. Department of Commerce, Springfield, Virginia

LEGAL NOTICE

This report was prepared as an account of Government sponsored work. Neither the United States, nor the Commission, nor any person acting on behalf of the Commission:

A. Makes any warranty or representation, expressed or implied, with respect to the accuracy, completeness, or usefulness of the information contained in this report, or that the use of any information, apparatus, method, or process disclosed in this report may not infringe privately owned rights; or

B. Assumes any liabilities with respect to the use of, or for damages resulting from the use of any information, apparatus, method, or process disclosed in this report.

As used in the above, "person acting on behalf of the Commission" includes any employee or contractor of the Commission, or employee of such contractor, to the extent that such employee or contractor of the Commission, or employee of such contractor prepares, disseminates, or provides access to, any information pursuant to his employment or contract with the Commission, or his employment with such contractor. 
Date Issued: August 4, 1965

Report Number $Y-1484$

Chemistry

TID-4500 (42nd Edition)

\section{UNION CARBIDE CORPORATION \\ Nuclear Division}

$$
Y-12 \text { PLANT }
$$

Contract W-7405-eng-26

With the US Atomic Energy Commission

THE PREPARATION OF RADIOACTIVE PHOSPHORUS-32

SOURCES ON METAL PLATES

W. C. Dietrich

R. E. Barringer

Oak Ridge, Tennessee

May 3, 1965 
Report Number Y-1484

Chemistry

TID-4500 (42nd Edition)

Distribution:

\begin{tabular}{|c|c|c|c|}
\hline Ballenger, H.F. & (2) & Keller, C. A. & $(A E C-O R O)(4)$ \\
\hline Barringer, R. E. & (10) & Kite, H. T. & \\
\hline Bender, M. A. & (ORNL) & Lewis, F. O. & (ORGDP) \\
\hline Briscoe, O.W. & & McLendon, J. D. & \\
\hline Burkhart, L. E. & & Mitchel, G. W. & \\
\hline Center, C.E. & (ORGDP) & Patton, F. S. & \\
\hline Christman, A. M. & & Rowan, J. H. & \\
\hline Cowen, D. D. & (ORNL) & Smith, W. T. & \\
\hline Dietrich, W. C. & & Waters, J. L. & \\
\hline Dow, Neal & & Whitson, W. K. & \\
\hline Fortenbery, M. J. & & Winkel, R. A. & (Paducah) \\
\hline Harwell, W. L. & $($ ORGDP)(5) & Zurcher, E. & \\
\hline Hemphill, L. F. & & $Y-12$ Central Files & (5) \\
\hline Huber, A. P. & (ORGDP) & $Y-12$ Central Files & $(Y-12 R C)$ \\
\hline
\end{tabular}

In addition, this report is distributed in accordance with the category, Chemistry as given in the "USAEC Standard Distribution Lists for Unclassified Scientific and Technical Reports", TID-4500 (42nd Edilion), June 1, 1965. 


\section{ABSTRACT}

A technique was developed for adhering phosphorous -32 to a tantalum or aluminum metal supporting plate. An aqueous radioactive solution was incorporated into a proprietary cement thinner (Sauereisen 14) and a measured quantity deposited on a metal plate. After drying and baking thoroughly, a uniform, hard, and tenacious radioactive source was produced. 
CONTENTS

INTRODUCTION....................... 5

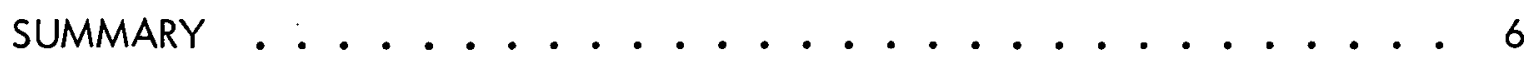

SOURCE PREPARATION. . . . . . . . . . . . . . . . . 7

Experimental Work ...................... . 7

Choice of a Coating Method . . . . . . . . . . . . 7

Choice of a Metal Backing . . . . . . . . . . . . . . 7

Uniformity and Quantitation of the Coating . . . . . . . . 8

Testing the Coatings . . . . . . . . . . . . . . 14

Recommended Procedure . . . . . . . . . . . . . . . . . 14

Materials Needed .................... 14

Solutions Used . . . . . . . . . . . . . . . . 15

Preparation Procedure .. . . . . . . . . . . . 15 


\section{INTRODUCTION}

An energetic beta source of phosphorous-32 mounted on a platinum metal plate was needed for one phase of a Gemini test program. The mounted radioactive material must meet the requirements suitable for space flight. Adherence, resistance to vibration and radioactivity, and stability toward changes in temperature, pressure, and moisture were prime considerations for the success of the experiment and the safety of the astronauts themselves. A known and reproducible quantity of radiation, evenly distributed, was also necessary.

This development effort was directed toward finding a suitable method to bind the radicactive material to the plate and to quantitate the procedure. 
A practical technique was developed for preparing a radioactive phosphorous -32 source mounted on a metal support plate. Aqueous phosphorous-32 solution was blended into Sauereisen 14, a proprietary cement thinner having a silicate base. A measured quantity of the mixture was pipetted onto a precoated metal plate (tantalum and aluminum were found suitable). After drying and baking thoroughly, a uniform, hard, and tenacious radicactive deposit remained.

Sources prepared in this manner withstood vibration, impact, moisture, temperature, and vacuum tests with virtually no effect.

Other materials in aqueous solution could be deposited in a similar manner by the procedure that was developed. 
SOURCE PREPARATION

\section{EXPERIMENTAL WORK}

Choice of a Coating Method

Several possible approaches were available for preparing phosphorous-32 sources affixed to a metal backing. Among the possibilities were: (1) electrodeposition on the metal, (2) incorporation of the radioactive material in an adhesive, and (3) absorbing the phosphorous into a matrix or sheet which could then be affixed to the metal backing. The most logical method appeared to be the second approach; namely, incorporation of the radioactive phosphorous into an adhesive which could then be applied to the metal.

Among known adhesives which could possibly meet the test requirements was one called Savereisen Insa-Lute Adhesive Cement 1.(a) This was suggested as a waterproof, liquid porcelain cement for metals that will not deteriorate at high temperatures. This cement likewise had the advantage of miscibility with aqueous solutions, the form in which phosphorous -32 was most readily available.

Choice of a Metal Backing

A mixture of Sauereisen paste (16.6 gms) with 2.4 milliliters of aqueous sodium phosphate solution to produce a $1 \%$ phosphorous concentration was applied to a platinum sheet. I. Ipon drying and gently warming under an infrared lamp, the cement pulled loose from the platinum backing. Various procedures were tried to roughen the surface of the platinum metal to improve adhesion; ie, anodizing, abrading with steel wool, and producing a coating of platinum black on the metal surface, butnone proved effective in improving adhesion.

Other metals were tried as backing material: copper, silver, and tungsten displayed poor adhesion with the Sauereisen cement; aluminum was found to provide excellent adhesion. Sauereisen cement spread on aluminum was dried in air and fired in an argon atmosphere at $500^{\circ} \mathrm{C}$ for 30 minutes. The resulting coating was hard, adherent, and water resistant. Aluminum, however, lacked one important feature; namely, adequate capability for shielding against beta radiation through the metal backing. As a possible alternative, an aluminum coating was vapor deposited on a platinum base. Sauereisen cement applied to this arrangement removed the aluminum from its platinum backing.

Tantalum was tried as a possible substitute for platinum and it was found that Sauereisen cement bonded well to the metal. Among the advantages of tantalum were: great

(a) Savereisen Cements Company; Fillsburyli, Pennsylvania. 
atomic density (resulting in good shielding characteristics), necessary structural rigidity, and significant savings in cost compared to platinum.

Uniformity and Quantitation of the Coating

One difficulty with the application of Savereisen 1 paste cement was in obtaining uniform coatings. Coating uniformity was significantly improved by using Sauereisen Thinning Liquid 14 which contained no inert filler material. The adhesive mixed with radioactive phosphorous -32 was applied by brushing. Although this procedure resulted in fairly uniform autoradiographs for a single coating (Figure 1) to good uniformity for a double coat (Figure 2), quantitation would be difficult in either case.

In an effort toward quantitation, a glass fiber filter paper disc was used in which a measured quantity of adhesive was absorbed. Sauereisen thinning liquid was colored with fluorescein as a visual tracer of uniformity. The adhesive was pipetted onto the glass fiber paper disc on a metal backing plate. The disc was bonded to the metal at the same time. After drying, examination showed a preferential migration to the outside of the disc with a consequent peripheral concentration of material as evidenced by the distribution of fluorescein.

A second attempt at quantitation called for the dilution of Savereisen 14 with water and pipetting an aliquot of the solution onto a prescribed area. Spreading the solution to cover the desired area proved very difficult due to the lack of wetting action on the metal. It was found that a light precoat of Sauereisen 14 facilitated the spread of the subsequent pipetted solution. A precoat of one part Sauereisen Thinning Liquid 14 and three parts water was brushed upon the prescribed area and dried in air.

A coating solution was prepared that consisted of one part Savereisen Thinning Liquid 14 and five parts of an aqueous dilution of phosphorous-32. When 0.5 milliliter of this solution was pipetted on each 1 1/2-inch-diameter circular area, the coating displayed serious peripheral concentration as shown by its autoradiograph (Figure 3 ). An improvement in uniformity was noted by doubling the volume of the coating solution to 1.0 milliliter, although a central deficiency is still noted in its autoradiograph (Figure 4). The coating solution was spread successfully by drawing the solution with the pipette tip to cause the material to run to the boundaries of the precoated area. It was imperative that all plates be absolutely level during the time the sources were prepared.

In an attempt to minimize the peripheral concentration, a more viscous coating solution was prepared from ten parts Sauereisen 14 and three parts aqueous phosphorous32 solution. Three-tenths milliliter of this mixture was pipetted upon each precoated circle on the tantalum plate. After air drying, the coating was cured in an oven at $200^{\circ} \mathrm{F}$. Autorndingraphs of this preparation (Figure 5) show good coating uniformity. 


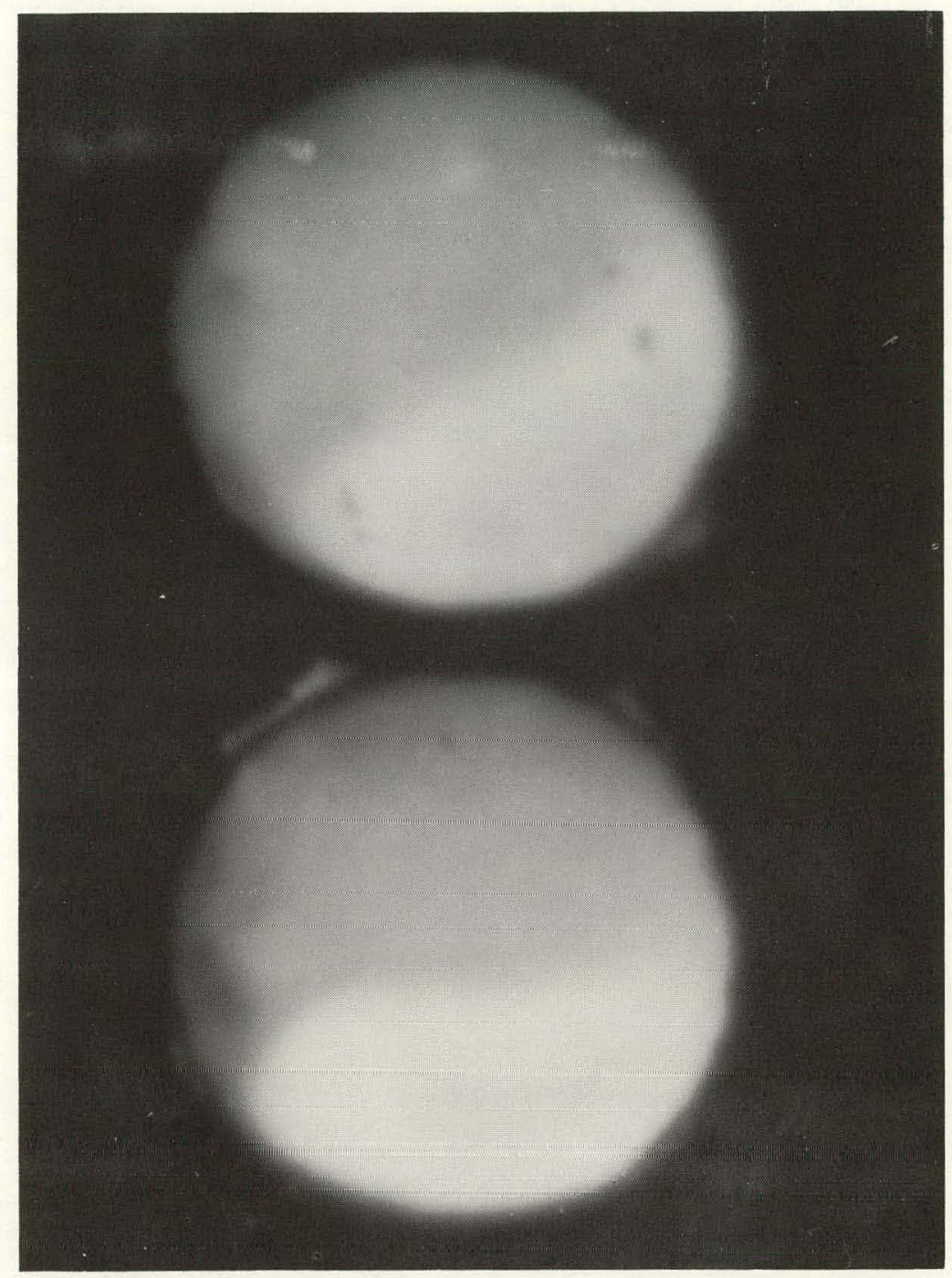

Figure 1. AUTORADIOGRAPHS OF A PHOSPHOROUS-32 SOURCE CONTAINING A SINGLE COATING OF THE SOLUTION. (1.6X) 


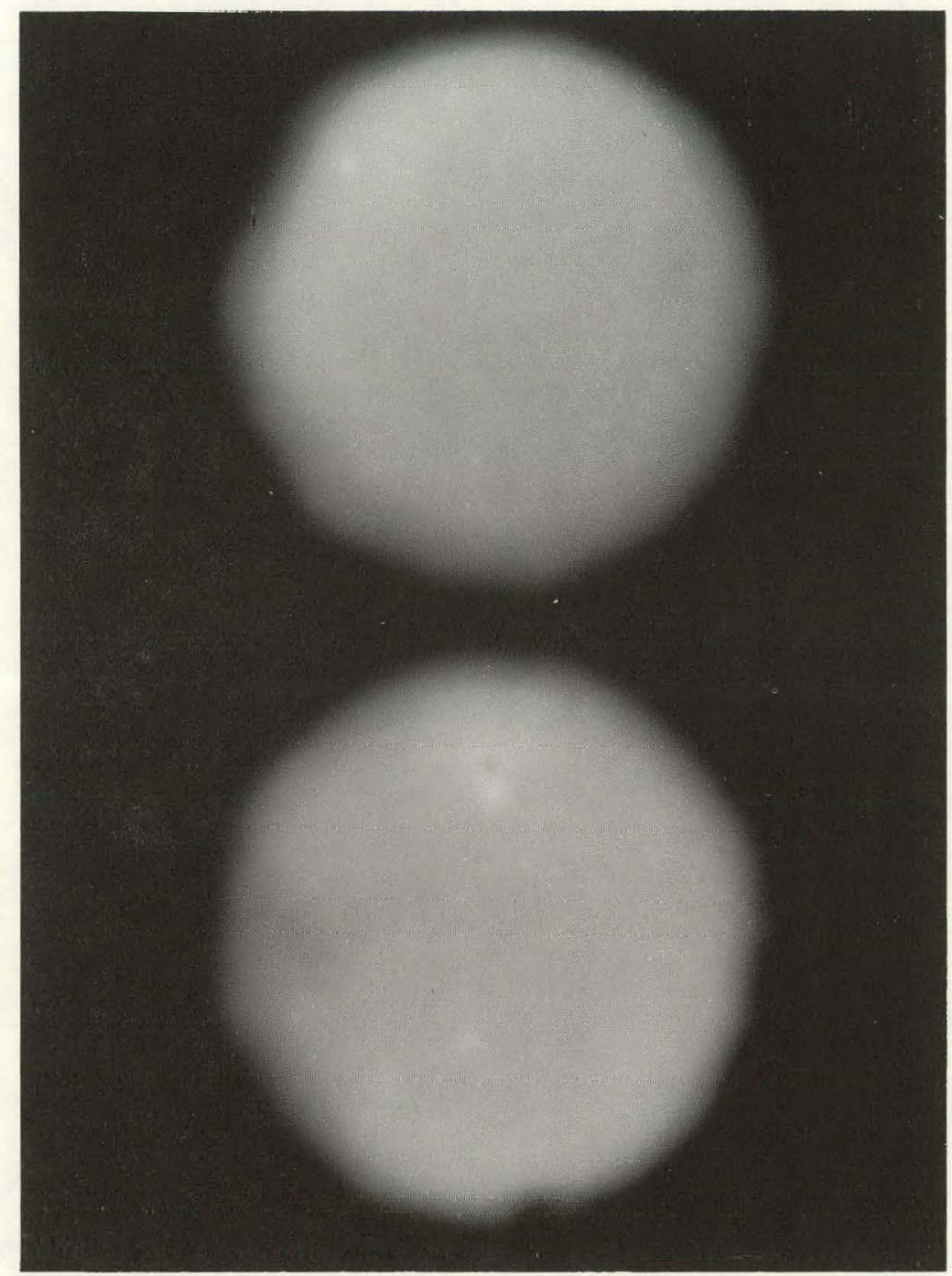

Figure 2. AUTORADIOGRAPHS OF A PHOSPHOROUS-32 SOURCE CONTAINING A DOUBLE COATING OF THE SOLUTION. (1.6X) 


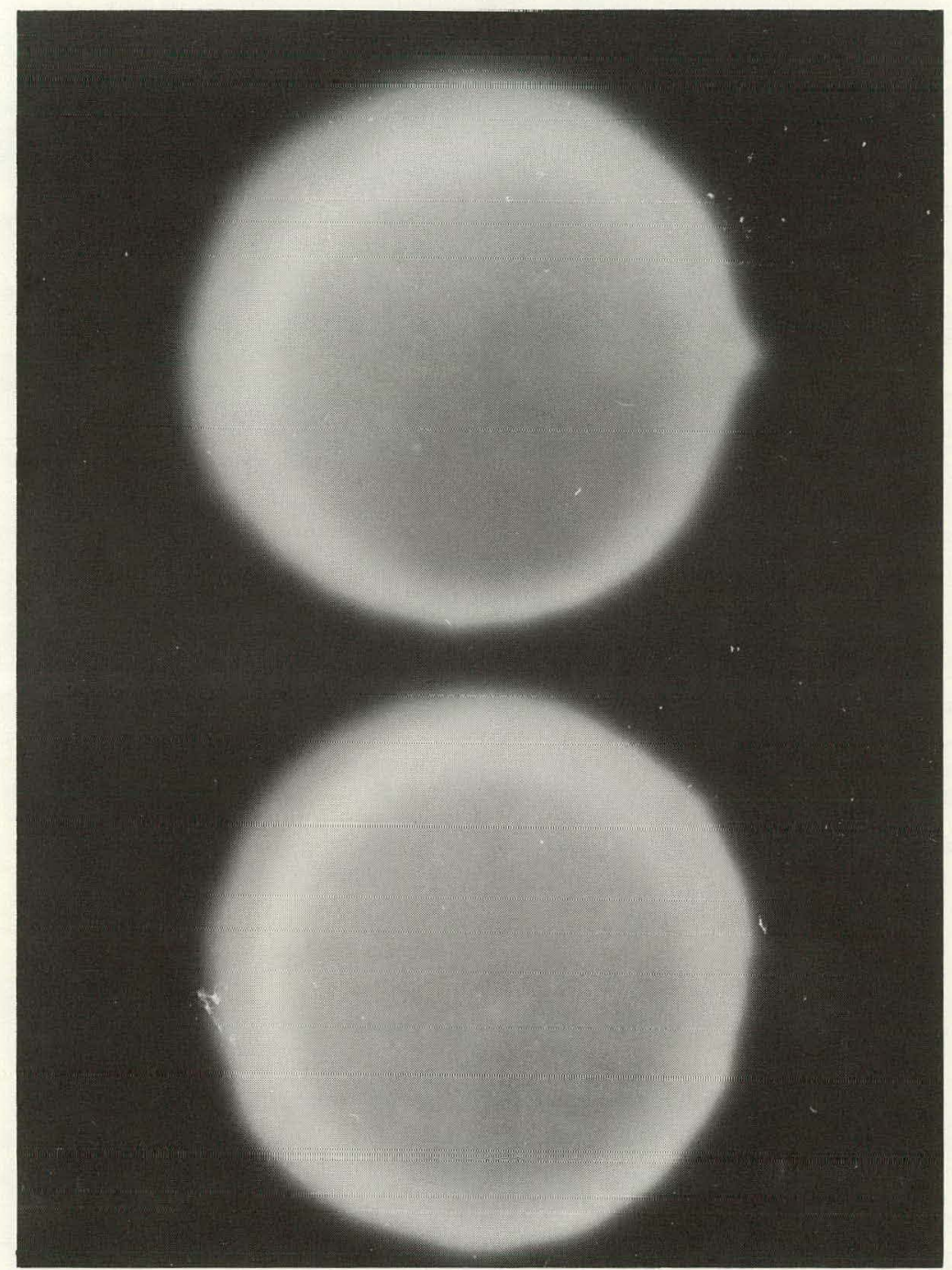

Figure 3. AUTORADIOGRAPHS OF A PHOSPHOROUS-32 SOURCE CONTAINING 0.5 MILLILITER OF A SOLUTION MADE OF ONE PART THINNING LIQUID AND FIVE PARTS AQUEOUS P.32. (1.6X) 


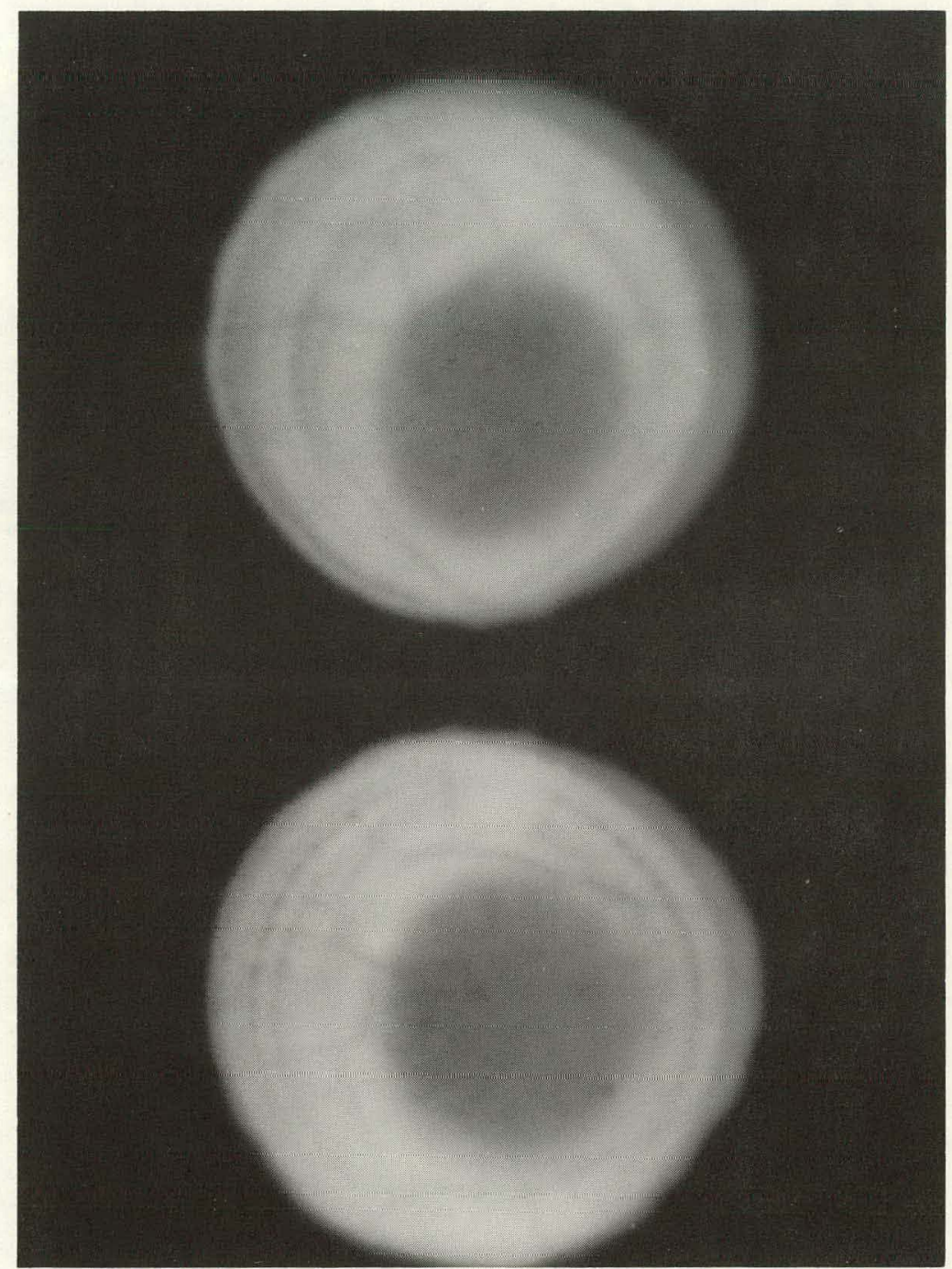

Figure 4. AUTORADIOGRAPHS OF A PHOSPHOROUS-32 SOURCE CONTAINING 1.0 MILLILITER OF A SOLUTION MADE OF ONE PART THINNING LIQUID AND FIVE PARTS AQUEOUS P-32. (1.6X) 


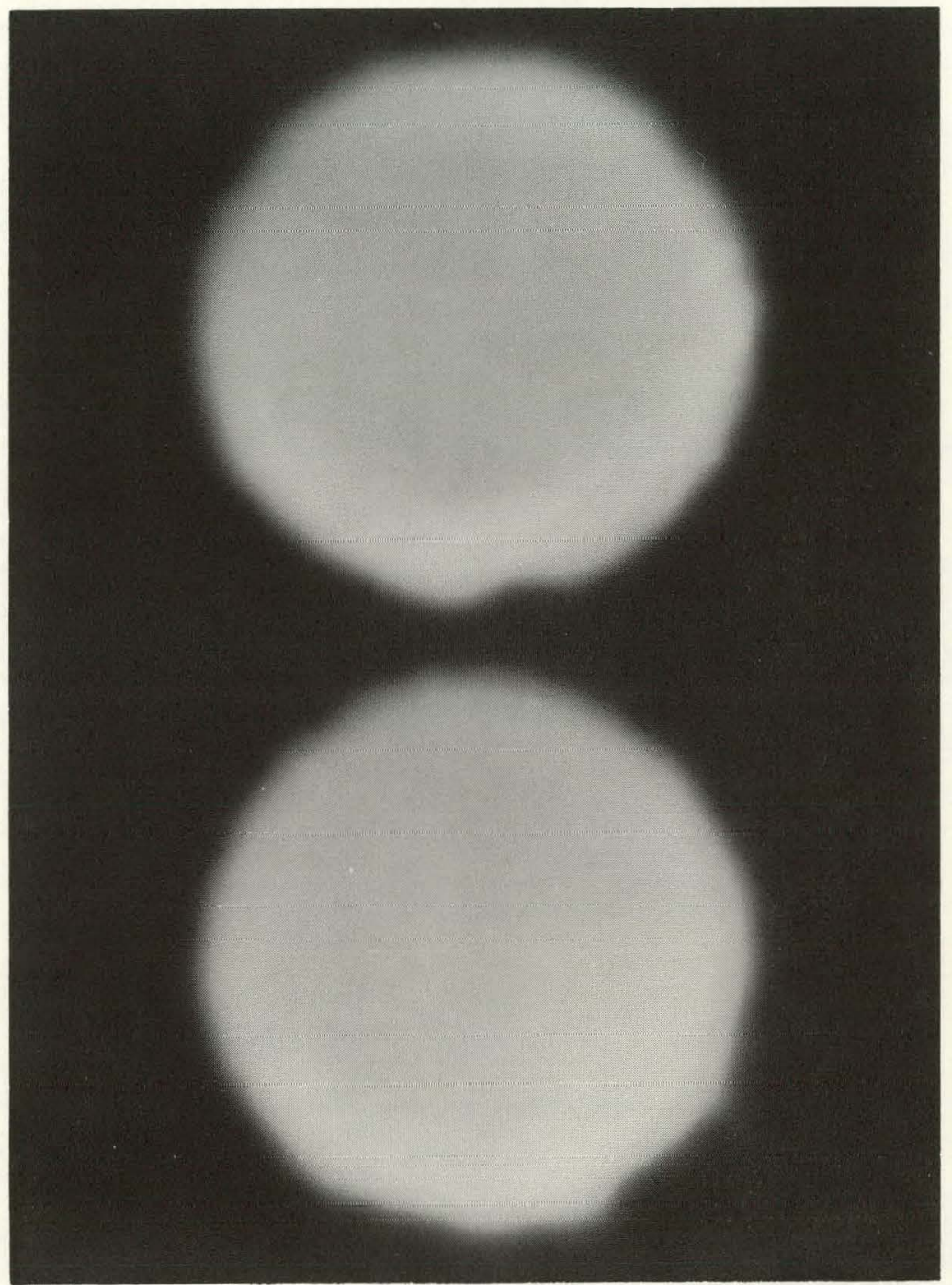

Figure 5. AUTORADIOGRAPHS OF A PHOSPHOROUS-32 SOURCE CONTAINING 0.3 MILLILITER OF A SOLUTION MADE OF TEN PARTS THINNING LIQUID AND THREE PARTS AQUEOUS P-32. (1.6X) 
This latter coating technique which produced adherent, uniform sources on a metal base (the tantalum combining both structural and shielding functions) formed the basis for the recommended technique.

Testing the Coatings

Sample sources produced by the recommended procedure successfully withstood the tests for temperature, vacuum, moisture, and vibration. Test coatings were subjected to $200^{\circ} \mathrm{F}$ at pressures $<10^{-5}$ torr for four hours. In a cold-humidity test, the source plates were chilled to $25^{\circ} \mathrm{F}$ and immediately exposed at room temperature to a moisture-saturated atmosphere, causing condensation of water droplets on the surfaces. After air drying for $1-2$ hours, the plates were placed in a vacuum chamber at $<10^{-5}$ torr overnight. During a vibration test the plates were subjected to forces of $8 \mathrm{G}$ at resonant frequencies for ten minutes along each of the two axes. No visible changes appeared in the coatings after completion of the tests.

An indication of the physical stability of the cement coatings was demonstrated by repeatedly impacting coated plates flat against a hard stone or metal surface. Usually no change was observed. Occasionally some cracking of the coating would occur but seldom was any piece dislodged. To remove the coating from the tantalum or aluminum backing, severe bending was required to crack the coat into small pieces plus physical scraping to pull the pieces away from the metal.

It was found necessary to dry the Sauereisen coat thoroughly by baking in an oven at $160^{\circ} \mathrm{F}$ for $11 / 2$ to 2 hours followed by a final bake at $200^{\circ} \mathrm{F}$ for two hours. With insufficient curing, the coating blistered when subjected to the vacuum test at $200^{\circ}$ F.

The recommended technique should be applicable to the preparation of sources other than phosphorous. Any water-soluble radioactive material could be incorporated into the Sauereisen thinner to prepare sources of varying characteristics.

\section{RECOMMENDED PROCEDURE}

\section{Materials Needed}

1. Savereisen Thinning Liquid 14.

2. Small camel's hair brush.

3. Measuring pipette. A one-milliliter serological pipette is suitable when equipped with a two-milliliter syringe attached to the top for accurate control of the pipetting. 
4. Lead-lined gloves that are elbow length.

5. Tantalum plates precut to the desired size.

6. Adequate plastic or glass shielding against beta radiation.

Solutions Used

1. Precoat consisting of one part by volume of Sauereisen Thinning Liquid 14 with 3 parts water.

2. Radioactive source solution made from a mix of one part by volume of Sauereisen Thinning Liquid 14 with 0.3 part of the aqueous phosphorous-32 solution. (All handling of $\mathrm{P}-32$ solutions must be done with adequate shielding against radioactivity.)

\section{Preparation Procedure}

1. Thoroughly clean the tantalum metal plates by a brief exposure to hydrofluoric acid and subsequent water rinse.

2. Outline on the plate with pencil the desired area to be covered by the P-32 source material.

3. Brush onto this area the precoat solution. Permit this coat to air dry.

4. Pipette the $\mathrm{P}-32$ source solution onto the plate $(0.3 \mathrm{ml} / 40 \mathrm{~mm}$ diameter circle). Using the tip of the pipette, spread the solution sufficiently to cause it to flow to the boundaries of the precoat. The plate must be on an absolutely level surface until air dried to a hard coat.

5. Place the air-dried plate in a drying oven at $70-75^{\circ} \mathrm{C}\left(\sim 160^{\circ} \mathrm{F}\right)$.

6. After $11 / 2-2$ hours, increase the temperature to $93-95^{\circ} \mathrm{C}\left(200^{\circ} \mathrm{F}\right)$ and maintain this temperature for at least two hours to complete the curing. 